\title{
Surgery of congenital and juvenile cataracts: a pars plicata approach with the vitrophage
}

\author{
GHOLAM A. PEYMAN, MOTILAL RAICHAND, AND MORTON F. GOLDBERG \\ From the Department of Ophthalmology, University of Illinois Eye and Ear Infirmary, Chicago, USA
}

SUMMARY Eighteen eyes with congenital cataracts were surgically managed by pars plicata lensectomy and vitrectomy using the vitrophage. No major intraoperative or postoperative complications were encountered. All eyes have maintained extremely clear media, attached retinas, and absence of pupillary block during a follow-up period ranging from 12 to 36 months.

In the last two decades numerous advances have been made in the management of congenital cataracts. The intraoperative and postoperative complications associated with discission, linear extraction, and intracapsular lens extraction have been reduced with the re-introduction of the aspiration technique (Scheie, 1960). Development of phacoemulsification instruments (Kelman, 1967; Shock, 1974; Girard, 1974) greatly simplified the aspiration procedure. However, such postoperative complications as secondary membrane formation continue to occur with these techniques and require additional surgery (Hiles and Wallar, 1974; Hiles and Hurite, 1973).

With the use of automated vitrectomy instruments a new dimension has been added to the treatment of congenital cataracts. Surgical approach through the limbus (Calhoun and Harley, 1975) and pars plicata (Peyman et al., 1977) has been described previously.

This report indicates our moderately long-term results in patients with congenital and juvenile cataracts who were managed with a pars plicata approach by combined lensectomy and vitrectomy using the vitrophage (Peyman and Sanders, 1975).

\section{Material and methods}

Seventeen patients (18 eyes) were referred for the management of congenital cataract to the Vitreous Service of the University of Illinois Eye and Ear Infirmary. In 14 patients the contralateral eye had been managed with other surgical techniques such as phacoemulsification and aspiration. In 1 patient

Address for reprints: Dr G. A. Peyman, Department of Ophthalmology, University of Illinois Eye and Ear Infirmary, 1855 West Taylor Street, Chicago, Ill. 60612, USA both eyes were managed by pars plicata approach as described below. The other patients had no previous surgery, and only 1 eye of each was operated on. In 1 of these the cataract was unilateral, and the other patient refused operation on the fellow eye.

The patients' ages ranged from 6 months to 37 years. Three patients were 25 years or older and the remainder were 15 or younger (Table 1). Patients 3 and 5 are twins. In 4 patients the cataracts were due to maternal infection with rubella during pregnancy; in 2 patients the family history suggested autosomal dominant mode of inheritance; and in the remainder the aetiology was unknown. In all the eyes combined lensectomy and vitrectomy was performed by means of the vitrophage (Peyman and Sanders, 1975).

In children surgery was performed with the patient under general anaesthesia. In adults local (retrobulbar) anaesthesia was used. Initially an examination of both eyes is done before the standard surgical preparation is made. Traction sutures are then passed through both eyelids, followed by traction sutures under the insertion of the 4 rectus muscles, 4-0 black silk being used. After adequate exposure is obtained, a limbal peritomy, usually in the infratemporal quadrant, is made. In children a 4-mm-long sclerotomy is made $2.5 \mathrm{~mm}$ posterior and parallel to the limbus, a No. 15 Bard-Parker blade being used. In adults, however, the sclerotomy can be made $3.5 \mathrm{~mm}$ from the limbus.

The underlying ciliary body is cauterised or diathermised gently. A mattress suture of 5-0 polyglactin 910 or 4-0 Supramid is passed through the lips of the sclerotomy, and a double throw-knot is applied loosely. The suture material is then looped out of the sclerotomy. A 52-s Beaver blade is inserted through the sclerotomy into the lens and then removed with a slicing motion to widen the 
Table 1 Patients treated with pars plicata lensectomy and vitrectomy

\begin{tabular}{|c|c|c|c|c|}
\hline $\begin{array}{l}\text { Case } \\
\text { no. }\end{array}$ & Age & $\begin{array}{l}\text { Aetiology and } \\
\text { remarks }\end{array}$ & Complications & $\begin{array}{l}\text { Approximate } \\
\text { clarity of } \\
\text { fundus view }\end{array}$ \\
\hline 1 & $14 \mathrm{yr}$ & Unknown & None & $20 / 20$ \\
\hline 2 & $5 \mathrm{yr}$ & Unknown & None & $20 / 20$ \\
\hline 3 & $4 \mathrm{yr}$ & $\begin{array}{l}\text { Rubella syndrome, } \\
\text { esotropia }\end{array}$ & None & $20 / 20$ \\
\hline 4 & $4 \frac{1}{2}$ yr & Rubella syndrome & None & $20 / 20$ \\
\hline 5 & $4 \mathrm{yr}$ & Rubella syndrome & $\begin{array}{l}\text { Transient corneal } \\
\text { oedema post- } \\
\text { operatively }\end{array}$ & $20 / 20$ \\
\hline 6 & $1 \frac{1}{y r}$ & Unknown, esotropia & $\begin{array}{l}\text { Self-limited } \\
\text { bleeding from } \\
\text { iris intra- } \\
\text { operatively }\end{array}$ & $20 / 20$ \\
\hline 7 & $6 \mathrm{mo}$ & $\begin{array}{r}\text { Autosomal dominant } \\
\text { congenital cataract }\end{array}$ & $\begin{array}{l}\text { Transient slight } \\
\text { corneal haze } \\
\text { postoperatively }\end{array}$ & $20 / 20$ \\
\hline 8 & $6 \mathrm{mo}$ & $\begin{array}{r}\text { Autosomal dominant } \\
\text { congenital cataract }\end{array}$ & None & $20 / 20$ \\
\hline 9 & $4 \mathrm{yr}$ & Rubella syndrome & None & $20 / 20$ \\
\hline 10 & $10 \mathrm{mo}$ & Unknown & None & $20 / 20$ \\
\hline 11 & $2 \frac{1}{2} \mathrm{yr}$ & Unknown & None & $20 / 20$ \\
\hline 12 & $15 \mathrm{yr}$ & $\begin{array}{r}\text { Aniridia and } \\
\text { nystagmus }\end{array}$ & None & $20 / 20$ \\
\hline 13 & $25 \mathrm{yr}$ & Chorioretinal scars & None & $20 / 20$ \\
\hline 14 & $34 \mathrm{yr}$ & Unknown & None & $20 / 20$ \\
\hline 15 & $8 \mathrm{yr}$ & Unknown & None & $20 / 20$ \\
\hline 16 & $37 \mathrm{yr}$ & Unknown, nystagmus & None & $20 / 20$ \\
\hline 17 & $6 \mathrm{mo}$ & $\begin{array}{l}\text { Autosomal dominant } \\
\text { congenital cataract }\end{array}$ & None & $20 / 20$ \\
\hline 18 & $7 \mathrm{mo}$ & Unknown & None & $20 / 20$ \\
\hline
\end{tabular}

tract for insertion of the lens fragmentor. A lens fragmentor (Peyman and Sanders, 1975) is introduced into the lens through the sclerotomy, and the lens material is fragmented for about 60 seconds.

After this the lens fragmentor is removed and replaced with a wide-angle cutter vitrophage (Peyman, 1975). The mattress scleral suture is tightened round the vitrophage. The cortical and nuclear fragments are removed first, followed by the lens capsule. An anterior and a central vitrectomy is performed to the optic disc, after which the vitrophage is removed and the scleral mattress suture tied. The conjunctiva is sutured with $6-0$ plain catgut. At the conclusion of the operation, antibiotic and cycloplegic eye drops are instilled.

In cases when the pupil does not dilate well sector iridectomy is performed with the vitrophage. The infusion fluid used for replacement of vitreous is $5 \%$ dextrose in $0.45 \%$ normal saline containing $2 \cdot 2 \mathrm{~g}$ sodium bicarbonate and $0.2 \mathrm{~g} /$ litre calcium chloride. We routinely add $4 \mu \mathrm{g} / \mathrm{ml}$ of gentamicin of infusion fluid.

\section{Results}

No operative complications were encountered in 17 eyes. One eye (Patient 6, Table 1) had minimal bleeding from the iris, which stopped spontaneously.

During the early postoperative period transient corneal oedema, noticed in 2 patients' eyes, cleared over a period of 2 to 3 weeks. There was no evidence of intraoperative or postoperative bleeding at the site of entry into the pars plicata or development of retinal dialysis. Surgery was tolerated well, and there was no obvious difference between the eyes with rubella- and non-rubella-induced cataracts during the postoperative period.

Postoperatively the media were extremely clear (approximately $20 / 20$ in clarity) in all eyes. As a majority of these patients have associated disorders such as amblyopia, microphthalmia, retinal scarring, or mental retardation, the final visual acuity was often difficult to assess.

No increase in intraocular pressure was noticed, and no severe or persistant intraocular inflammation appeared. No retinal detachment has been evident during the follow-up, ranging from 12 to 36 months. No case of pupillary block with shallow anterior chamber occurred.

\section{Discussion}

Management of congenital cataracts, a matter of great controversy, can be separated into three main areas of debate: the indication and timing of surgical intervention; the technical procedures of choice; and the management of amblyopia and postoperative optical correction. Our discussion will be confined to the technical aspects of congenital cataract surgery, although it is recognised that restoration of good visual function often depends on postoperative management and correction of amblyopia.

Despite the availability of various surgical techniques no one procedure has gained wide acceptance because of inherent complications associated with each. The simple discission technique had an unacceptable rate of complications such as swelling or retained lens matter, glaucoma, and retinal detachment (Barkan, 1932; Chandler, 1951; Cordes, 1956). Although better results have been reported with linear extraction (Owens and Hughes, 1948; Bagley, 1949), this technique was also 
associated with complications such as delayed formation of anterior chamber, anterior synechiae and updrawn pupil, occlusion of pupil, membrane formation, vitreous loss, glaucoma, and retinal detachment (Cordes, 1961). Similarly, intracapsular extraction produced complications in a very high percentage of cases (Ryan et al., 1965) and was advocated by only a few surgeons (Escapini, 1968).

The aspiration techniques have greatly reduced the complications associated with older methods (Sheppard and Crawford, 1973). Although the incidence of postoperative glaucoma and retinal detachment was reduced significantly (Parks and Hiles, 1967; Ryan et al., 1965; Ryan and von Noorden, 1971), secondary membrane formation and vitreous loss have continued to be major problems. Parks and Hiles (1967) reported a 73\% incidence of membrane formation and $6 \%$ vitreous loss in a review of 52 eyes that underwent discission and aspiration. Ryan and von Noorden (1971) reported $23 \%$ incidence of secondary membrane and $8 \%$ vitreous loss in 75 cases by using the discission and the aspiration technique. The incidence of postoperative secondary membrane formation with aspiration techniques ranged from $18 \%$ (Sheppard and Crawford, 1973) to $73 \%$ (Parks and Hiles, 1967).

Although phacoemulsification has greatly facilitated the surgical management of congenital cataract surgery, complications such as vitreous loss and secondary membrane formation are still major problems that often require additional surgery (Hiles and Hurite, 1973). Hiles and Wallar (1974) reviewed their experiences with phacoemulsification and aspiration in infantile cataract surgery in $\mathbf{3 9 0}$ eyes. They reported secondary or delayed posterior capsulotomies in $66 \%$ of their aspiration group and $39 \%$ in their phacoemulsification group. A total of $70 \%$ of the eyes in the aspiration series required a capsulotomy either at the end of the operation or later. Of those eyes undergoing phacoemulsification $58 \%$ required a capsulotomy. Hiles (1977) states that as many as $92 \%$ of these children will need capsulotomies if enough time has elapsed after the original cataract surgery.

Automated vitrectomy instruments have greatly aided our ability to deal with secondary membrane and vitreous loss. Although we have advocated the pars plana approach for adult patients, we suggest the pars plicata approach for children. Anatomically the pars plana region is smaller in children than in adults. By making the sclerotomy $2.5 \mathrm{~mm}$ from the limbus and entering the eye through the pars plicata a safe distance from the ora serrata is maintained. Transillumination through the pupil is sometimes helpful in identifying the ciliary body.
The pars plicata approach offers many advantages over the limbal approach. With the limbal aproach Calhoun and Harley (1975) reported unplanned iridectomies in $14 \%$ of cases and a similar incidence of unexplained prolonged intraocular inflammation. The pars plicata route avoids direct manipulation of the corneal endothelium, and, similarly, contact with the iris is kept to a minimum. Any accidental bleeding from the iris into the deep vitreous can be treated immediately with the pars plicata approach, because a fundus contact lens can immediately be placed on the unmanipulated cornea. Moreover, lens particles that may fall into the vitreous can also be retrieved, so that the chance of postoperative inflammation is thus reduced. With the pars plicata approach the tip of the vitrophage can easily reach behind the iris and remove most of the lens material by applying only suction, a procedure which is rather difficult through the limbal approach, particularly in the axis of the shaft of the instrument.

In our series no patient has had severe intraocular inflammation postoperatively. We routinely remove the anterior vitreous with a central core of vitreous down to the optic disc. This technique has eliminated the development of pupillary block glaucoma.

Our patients have been followed up for periods ranging from 12 to 36 months. All eyes have maintained extremely clear media postoperatively. Using serial refraction measurements, we have been able to observe normal growth and development in these eyes when compared with contralateral eyes. With the evidence at hand we can postulate that pars plicata lensectomy and vitrectomy has no immediate untoward effect on the development of infant eyes. Although additional long-term results of this technique are clearly desirable, the present data are encouraging.

Combined pars plicata lensectomy and vitrectomy offers a 'one procedure' technique for the surgical management of congenital cataracts with minimal complications.

This investigation was supported in part by NIH training grant PH SEY 703801, a grant from the Lions of Illinois Foundation, and by an unrestricted grant from Research to Prevent Blindness Inc., NYC.

\section{References}

Bagley, C. H. (1949). Congenital cataracts: a survey of the various types of operation. American Journal of Ophthalmology, 32, 441-419.

Barkan, O. (1932). A procedure for the extraction of congenital, soft and membranous cataracts. American Journal of Ophthalmology, 15, 117-124.

Calhoun, J. H., and Harley, R. D. (1975). The roto-extractor in pediatric ophthalmology. Transactions of the American Ophthalmological Society, 73, 292-305.

Chandler, P. A. (1951). Surgery of the lens in infancy and childhood. Archives of Ophthalmology, 45, 125-138. 
Cordes, F. C. (1956). Failure in congenital cataract surgery: A study of fifty-six enucleated eyes. Transactions of the American Academy of Ophthalmology and Otolaryngology, 60, 345-367.

Cordes, F. C. (1961). Linear extraction in congenital cataract surgery. American Journal of Ophthalmology, 52, 355-367.

Escapini, H. (1968). Intracapsular extraction of congenital cataract. American Journal of Ophthalmology, 66, 683-687.

Girard, L. J. (1974). Cataract extraction by ultrasonic aspiration, vitrectomy by ultrasonic aspiration. Transactions of the American Academy of Ophthalmology and Otolaryngology, 78, 50-59.

Hiles, D. A. (1977). Phacoemulsification of infantile cataracts. International Ophthalmology Clinics, 17, 83-102.

Hiles, D. A., and Hurite, F. G. (1973). Results of the first year's experience with phaco-emulsification. American Journal of Ophthalmology, 75, 473-477.

Hiles, D. A., and Wallar, P. H. (1974). Phacoemulsification versus aspiration in infantile cataract surgery. Ophthalmic Surgery, 5, 13-16.

Kelman, C. D. (1967). Phaco-emulsification and aspiration: a new technique of cataract removal: a preliminary report. American Journal of Ophthalmology, 64, 23-35.

Owens, W. C., and Hughes, W. F. (1948). Results of surgical treatment of congenital cataract. Archives of Ophthalmology, 39, 339-350.

Parks, M. M., and Hiles, D. A. (1967). Management of infantile cataracts. American Journal of Ophthalmology, $63,10-19$

Peyman, G. A. (1975). Wide-angle cutter vitrophage. Ophthalmic Surgery, 7, 96-97.

Peyman, G. A., and Sanders, D. R. (1975). Modern methods of vitreous surgery. In Advances of Uveal Surgery, Vitreous Surgery, and the Treatment of Endophthalmitis, p. 113 Appleton-Century-Crofts: New York.

Peyman, G. A., Sanders, D. R., Marc, R., and Korey, M. (1977). Vitrophage in management of congenital cataracts. Albrecht von Graefes Archives für Klinische und experimentelle Ophthalmologie, 202, 305-308.

Ryan, S. J., Blanton, F. M., and von Noorden, G. K. (1965). Surgery of congenital cataract. American Journal of Ophthalmology, 60, 583-587.

Ryan, S. J., and von Noorden, G. K. (1971). Further observations on the aspiration technique in cataract surgery. American Journal of Ophthalmology, 71, 626-630.

Scheie, H. G. (1960). Aspiration of congenital or soft cataracts: a new technique. American Journal of Ophthalmology, 50, 1048-1056.

Sheppard, R. W., and Crawford, J. S. (1973). The treatment of congenital cataracts. Survey of Ophthalmology, 17, 340-347.

Shock, J. P. (1974). Phacocryolysis combined with phacofragmentation and irrigation for removal of cataracts. American Journal of Ophthalmology, 77, 860-864. 